\title{
Gorillas-A Survey
}

\section{Don Cousins}

Part One of this survey of the three gorilla races-western lowland, eastern lowland and volcano-was published in the last Oryx (June 1978) and covered the western lowland gorillas. Eastern lowland and volcano are discussed below.

\section{Eastern Lowland Gorillas}

Eastern lowland gorillas inhabit a vast area of humid rain forest in the Zaire basin, including the Utu Mwenga-Fizi and Tshiaberimu regions. Aframomum (Zingiberacae) is a major food for both lowland races, and Schaller postulated that the wide distribution of gorillas coincides with its occurrence. Sabater Pi discovered that the seed passes unharmed through the gastro-intestinal tract to take root in the gorilla faeces. Because the eastern lowland gorilla's diet, particularly in the Utu region, is similar to that of the western race, his activities in many areas revolve around the cultivation of man, thus producing the same pattern of plantation destruction and hunting reprisals.

The major eastern lowland gorilla populations are confined to Zaire north of the Zaire river, where, despite a dense human population (171/2 million in less than one million sq miles), conservation measures have been stepped up since independence in 1960. By 1970 the three national parks had been increased to seven, with more promised. The maiko National Park $(1,000,000 \mathrm{ha})$ contains eastern lowland gorillas, and also okapi, only recently discovered in the area.

Before independence gorillas were often killed by Europeans. A Belgian mine official in the Utu region admitted to Schaller that he had shot nine, and in 1948 officials organised a capture expedition at Angumu in which 60 gorillas were killed to capture eleven infants, only one of which survived. In 1957 Charles Cordier trapped a whole family of eastern lowland gorillas near Bukavu for the International Scientific Foundation for the making of the film 'Lords of the Forest'; these were later studied by biologists in semi-captive conditions. Charles Cordier made other successful trappings, and in the late 1950s and early 1960s a spate of eastern lowland gorillas found their way into various zoological collections. Antwerp received 6, London 2, Chester 2, Hanover 1, Bronx 3, Oklahoma 2, San Diego 1, and Japan Monkey Centre 2. In recent years very few, if any, have left Zaire.

\section{Uganda}

An isolated population of around 200 eastern lowland gorillas exists in Uganda's Kayonza Forest, in the Impenetrable Forest Reserve. In this forest area of 96 square miles they appear to have little contact with man, although it is reported that they occasionally fall victim to the Batwa pygmies' deadfalls set to trap forest pigs. In 1971 Dr Beck of Brookfield Zoo saw little disturbance from lumbering and agriculture and no livestock grazing.

\section{Volcano Gorillas}

The volcano gorillas are restricted to five of the eight Virunga volcanoesMikeno, Karisimbi, Sabinio, Visoke and Mahuvura - and to Mt Kahuzi, west of Lake Kivu, in Zaire. The Virunga volcanoes are shared by three African 
nations-Zaire, Rwanda and Uganda-the Zaire section being part of the Virunga National Park (formerly the Albert) covering 800,000 ha. In the early days of independence this sanctuary went through a bad period and 22 unarmed park guards were killed by poachers, but today it is the best protected sector of the Virunga range. Adjacent to it, on the Rwanda side, is the Volcanoes National Park (23,000 ha) where, at the Karisoke Research Centre, Dian Fossey has been studying the gorillas since 1967. There have been several unexplained incidents of gorillas being killed, and the gorilla area is frequently invaded by cattle. Her esimate of the numbers in the park is only $279^{\star}$ and the ratio of infants to juveniles and mature animals is low. In Uganda the so-called Gorilla Sanctuary is little more than a title and poaching is rife. Cadavers of adult males have been found with ears, tongue, genitals and toes missing, the motive apparently being 'sumu' (black magic).

The best protected population of volcano gorillas is that of the 250 or so animals living in the National Park of Kahuzi-Biega (60,000 ha) in Zaire. The protector of this sanctuary is a Belgian, Adrien Deschryver, who is on such friendly terms with several gorilla groups in the park that visitors can be guaranteed a sight of the gorillas during their stay. One gorilla group in the park comprises 22 animals. Deschryver has made range surveys and puts the gorilla boundaries at Lake Kivu (east), Fizi (south), Lobutu (west), and Bafwasende (north). In appearance and habits these gorillas seem to differ from those in the Virunga Volcanoes, which appear to be distinct and possibly the only surviving population of $G$. g. beringei. The Kahuzi gorillas seem more aptly to belong to $G$. $g$. graueri, and there is evidence that they wander down into the lower forests. Despite full protection gorillas are often killed outside the park, mainly for meat, but also for sale. Deschryver is working on plans for an extension of the park to include the majority of Zaire's gorillas.

\section{Conclusions}

This survey of the gorilla situation is pock-marked with gaps and leaves many questions unanswered, but I believe that the following conclusions can be safely drawn:

It seems certain that the western lowland gorilla will disappear from some of the African countries it now inhabits, notably Equatorial Guinea and the Central African Republic. In the south-western forests of Eastern Cameroon the outlook for them is poor, but the south-eastern forests are still sufficiently remote to afford some protection, although timber companies have their plans even here. The isolated populations in West Cameroon are still something of an unknown quantity, but there are no reports of destruction and no infants have found their way into zoos.

In Gabon and Congo the situation is much brighter. Laws against illegal trafficking in infant gorillas are enforced, there is no human population pressure, the reserves that contain gorillas are inaccessible, and there are still large tracts of uninhabited forest. Nevertheless, to conserve a species you have to know its requirements, and few field studies have been made of the western gorilla such as Dian Fossey has done for the volcano gorilla. This is where primate centres such as the one at Makokou could play an important role.

Comprehensive ecological and behavioural studies have also yet to be made on the even less known eastern lowland gorilla. Schaller did some work on this subspecies during his classic study of the volcano gorilla but his time was $\star^{\star}$ Now reduced to $c$. 225 . 
severely limited. Eastern gorillas are undoubtedly killed by indigenous tribes, and habitat destruction affects them in some areas, but there are still vast areas where gorillas and their forest habitat are not threatened. Except in the Kahuzi region, the outlook for the volcano gorilla also is pessimistic. The Virunga volcanoes are no longer a secure stronghold, and even on the Zaire side there is poaching. In Uganda especially the seeds of extinction have been sown.

Ten African nations hold the gorilla's future in their hands. All are newly emergent countries and all have their political teething problems; if they decide that the habitat must go nothing can save the gorillas. Fortunately some African nations, like Zaire, take a pride in their natural inheritance and its conservation and the magnificent gorilla may be saved.

\section{Acknowledgments}

I have corresponded with or spoken personally to many people who have recently worked in Africa and I am indebted to them for much valuable information. All these contributors are gratefully acknowledged.

\section{References}

DENIS A. 1963. On Safari. Collins, London.

JONES, C. and J. SABATER PI.1971. Comparative ecology of Gorilla gorilla (Savage and Wyman) and Pan troglodytes (Blumenbach) in Rio Muni, West Africa. Bibliotheca Primat. no. 13.

MARCH, E. W. 1957. Gorillas of Eastern Nigeria. Oryx 4, 30-34.

MERFIELD, F. G. 1954. The Gorilla of the French Cameroon. Zoo Life 9, 84-94. SCHALLER, G. B. 1963. The Mountain Gorilla: ecology and behaviour. University of Chicago Press.

\section{Anything for Fun}

Mexican free-tailed bats Tadarida brasiliensis mexicana in the south-western US have been declining steadily because pesticides are killing off their food supply. Another quite gratuitous threat is described by Michael G. Petit, in Natural History. During his survey of the bats in Eagle Creek Cave in Arizona's Gila Mountains he saw a caravan of twelve vehicles go down the canyon toward the cave. Then there were gunshots and a sprinkling of bats flying back and forth overhead. At the cave entrance (out of sight of the roosting area) he found a shotgun cartridge and a .45-calibre shell which could only have been fired to panic the animals into flight. Three days later he found a pile of 85 dead baby bats on the cave floor, suggesting that the stress caused by the gunshots had made them lose their grip. These bats have been declining by about 10 per cent per year since the early 1950 s, when there were 100,000 in the cave.

\section{How DDT Killed Birds in a Zoo}

When all but one of Los Angeles County Zoo's Brant's and guanay cormorants and all the California gulls developed tremors and died, autopsies revealed lethal concentrations of DDT in their livers and brains. How birds kept in a zoo for 6-7 years could be poisoned by an illegal chemical was answered by the discovery of DDT in their principal food, the queenfish Seriphys politus, caught off the Palos Verdes Peninsula within $20 \mathrm{~km}$ of the main outfall of the Los Angeles County Joint Water Pollution Control Plant. Though it had been six years since the plant had discharged any DDT, residues in sediments on the seabed were being gradually released, and taken in by the fish and ultimately by the zoo's birds; these were more vulnerable than wild birds because of their steady diet of one species from one small area. 